\title{
Natural Genetic Variation for Grapevine Phenology as a Tool for Climate Change Adaptation
}

\author{
Silvina van Houten ${ }^{1}$, Claudio Muñoz ${ }^{1}$, Laura Bree ${ }^{2}$, Daniel Bergamín ${ }^{2}$, Cristobal Sola ${ }^{2}$ \\ and Diego Lijavetzky ${ }^{1, *}$ (D) \\ 1 Instituto de Biología Agrícola de Mendoza (IBAM, CONICET-UNCuyo), Almirante Brown 500, \\ Chacras de Coria, M5528AHB Mendoza, Argentina; \\ silvivanh@gmail.com (S.v.H.); cmunoz@fca.uncu.edu.ar (C.M.) \\ 2 Vivero Mercier Argentina, Ruta 40 Km 3273, Perdriel, M5509 Mendoza, Argentina; \\ lbree@viveromercier.com.ar (L.B.); dbergamin@viveromercier.com.ar (D.B.); cjdsola@yahoo.com.ar (C.S.) \\ * Correspondence: dlijavetzky@conicet.gov.ar
}

Received: 15 June 2020; Accepted: 24 July 2020; Published: 12 August 2020

check for updates

Featured Application: This article belongs to the Special Issue Climate Change Impact on Viticulture and Potential Adaptation Strategies.

\begin{abstract}
Grapevine phenology is being modified by climate change, particularly by the increase of temperatures that affect grape attributes for wine production. Besides the existing oenological and viticultural approaches, the thorough exploration of the current intra-cultivar genetic variability to select late-ripening genotypes emerges as an interesting alternative. In the present work, we have analyzed the natural genetic variation for phenology and agronomic traits among 21 'Malbec' clones and we demonstrated that fruiting cuttings are a useful tool for the analysis of such variation in 'Malbec'. Several clones could be distinguished by agronomic traits like berry number or cluster weight, and mainly by phenology characteristics like the length of the phase between flowering and veraison, which reached more than 16 days between early and late clones. These results support the approach of exploring grapevine clone collections in searching for genotypes with delayed phenology, and thus with the potential to maintain some expected quality characteristics under warm conditions.
\end{abstract}

Keywords: Vitis vinifera L.; 'Malbec'; climate change; fruiting cuttings; clonal genetic variability; high temperature; phenology

\section{Introduction}

Climatic conditions have changed over the past decades, and simulations with different scenarios of greenhouse gas emissions show that the observed tendencies will continue in the near future and the real situation is worse than the more pessimistic prediction [1]. According to the Intergovernmental Panel on Climate Change (IPCC, www.ipcc.ch), the increase of global mean surface temperature by the end of the 21st century (2081-2100), relative to the current reference period (1986-2005), is likely to be from $0.3{ }^{\circ} \mathrm{C}$ to $4.8^{\circ} \mathrm{C}$ depending on the mitigation scenario. In addition, it is likely that heat waves will occur with higher frequency and longer duration as a consequence of the increase in temperature variability.

Among human activities, agriculture and particularly viticulture, are highly dependent upon climatic conditions during the growing season. Grape berry composition is known to be highly sensitive to environmental conditions, with the temperature being one of the most critical environmental factors during berry development and ripening [2]. Many studies have linked the temperature rise to accelerated phenology, with the potential to greatly affect grape attributes for red table wines 
production [3-5]. For example, increased temperatures have been reported to advance budburst, flowering, and to hasten berry development [6-8]. Simulations using a model for the developmental stages of Riesling and Gewurztraminer predict earlier onset of veraison (up to 23 days before), by the end of the present century compared with its timing in 1976-2008, resulting in an important increase in mean temperatures (more than $7^{\circ} \mathrm{C}$ ) during the ripening period [9]. Such changes are likely to have a substantial impact on grape and wine quality. One of the clearest relationships between temperature and fruit quality concerns grape berry acidity, as high temperatures reduce the concentration of organic acids, especially malic acid, desynchronizing sugar, and organic acid metabolisms [10]. In addition, high temperatures during ripening may decrease anthocyanin concentration in grapes, due to the inhibition of anthocyanin biosynthesis, chemical or enzymatic degradation and/or the imbalance in the expression and function of specific transmembrane transporters [5]. In previous studies, seed ripening was advanced in relation to other berry tissues, and this asynchrony may have direct oenological implications affecting the resultant phenolic composition and sensory attributes of wines $[10,11]$.

Several approaches have been assessed in order to avoid quality alterations caused by high temperatures. Oenological approaches like the use of yeast strains producing less alcohol yield [12] or viticultural practices including modifications of training systems (higher trunks, late pruning, minimal pruning of reduced leaf area to fruit weight ratios) were thoroughly investigated [13]. On the other hand, changes in vineyard location (higher latitudes and/or altitudes) may be possible in some regions, but not in countries with a "terroir"-based viticulture [14]. However, if the objective is to maintain wine typicity, one alternative is to explore in-depth the existing intra-varietal genetic variability in each cultivar to select late-ripening genotypes [14]. By this approach, it could be possible to identify clones with several weeks of ripening delay. [15].

Variability is an intrinsic property of all biological systems, including grapevine, and may occur at different levels. Thus, considering the great diversity within the Vitis genus, the genotype is an important source of variability [16]. Since most wine grape varieties are reproduced by vegetative propagation, spontaneous mutations can accumulate over time. When these natural events have significant phenotypical effects, the new plant can bear interesting traits, thus leading to somatic variants within a variety that can be exploited for clonal selection and propagation [17]. During the last two centuries, clonal selections were performed to improve vineyard health and production traits like yield, precocity, flavor, and color among others $[17,18]$. The need to evaluate grape variability (both genetic diversity and phenotypic plasticity) is further increased by ongoing climate change. The existing clone collections worldwide can be explored to detect any phenotypic variation that could be effective means of adaptation to climate change, looking for either late-ripening clones or clones with a high ability to maintain some required characteristics under warmer conditions [13].

Several previous studies showed the evaluation and use of grapevine fruiting cuttings to study the development of vegetative and reproductive plant traits, as well as to analyze particular physiological responses [2,4,15,19-24]. Most of these reports are focused on the study of one cultivar or the comparison between different cultivars, with the exception of the work of Arrizabalaga et al. [15], where the authors analyzed the response of 13 'Tempranillo' clones to elevated temperatures. Thus, we present here a thorough analysis of the intra-cultivar natural genetic variation for phenology and berry development traits on a collection of 21 clones by setting up the fruiting cutting system in cultivar 'Malbec'.

\section{Materials and Methods}

\subsection{Plant Material}

Twenty-one clones of Vitis vinifera L. cv. 'Malbec' were studied in the present study. The material belongs to the Mercier Argentina nursery collection located at Pedriel (Lujan de Cuyo, Mendoza, Argentina). The collection was developed by the nursery in 2001 from 'Malbec' selections from five vineyards distributed along Lujan de Cuyo and Valle de Uco (http://viveromercier.com.ar/). The clones were sorted in rows with 10 genotypes per row. The vineyard was a homogeneous field without slope. 
Each experimental unit (clone) was represented by five plants. During the 2018 season, three vines of each clone were selected visually according to the vigor. At the pruning time, dormant cuttings of $40-50 \mathrm{~cm}$-long were collected.

\subsection{Fruiting Cutting Growing Conditions}

The growing conditions were performed according to Lebon et al. [21] with minor modifications. Briefly, ca. 50 cuttings per clone were treated with a Captan $\left(2 \mathrm{~g} \mathrm{~L}^{-1}\right)$ to prevent contamination, stored in the dark for 4 weeks at $4{ }^{\circ} \mathrm{C}$. After $12 \mathrm{~h}$ of hydration and acclimation at $25^{\circ} \mathrm{C}$, the proximal extremities of the cuttings were dipped in indol-3-butyric acid (IBA) at $300 \mathrm{ppm}$ for $8 \mathrm{~h}$ to promote rhizogenesis and set in a "hot bed" inside a cool room. Once cuttings had developed roots ( 3 weeks, Figure 1a), they were transplanted to $0.3 \mathrm{~L}$ pots and transferred to a shade house with natural conditions. Plants grew with natural light and were irrigated with the nutritive solution described by [25]. Under these conditions, bud-break took place after 1 week (Figure 1b). Only one leaf was allowed to grow in the developing shoot, manually removing the others. At the stage of the separated cluster, they were transplanted to $3 \mathrm{~L}$ pots. The tip of the shoot was manually excised above the inflorescence. A new shoot (lateral) was then allowed to develop and support the vine. Only one inflorescence was allowed to develop on each plant, manually excising the rest (when and if they appeared as shown in Figure 1c). Until fruit set, the vegetation of the lateral shoot was controlled and only four leaves per plant were allowed to grow. We then monitored the reproductive development by scoring the stages of veraison (Figure 1d) and harvest (Figure 1e).


Figure 1. Developmental stages of 'Malbec' fruiting cuttings. (a) cuttings showing root development on removal from the heated container after four weeks; (b) budburst; (c) fruit set; (d) veraison; (e) the same cluster at harvest.

\subsection{Phenology Assessment}

Fruit set, flowering time ( $50 \%$ of opened flowers), veraison ( $50 \%$ of colored berries) were visually assessed through daily observations and each event was individually determined for each plant. Harvest time was determined as 60 days after veraison according to previous assays in the same location. The phenological development was established as the elapsed time between flowering and veraison (Figure S1).

\subsection{Harvest Sampling}

At harvest, bunches were weighted and all berries from each bunch were separated and counted to determinate berry weight. Then, they were crushed and processed to estimate ${ }^{\circ} \mathrm{Brix}$ a measure of the total soluble solids using a digital portable refractometer (Hach, Loveland, CO, USA).

\subsection{Statistical Analysis}

Statistical tests were carried out using R [26] with the help of RStudio [27]. The Shapiro-Wilk normality test was performed for each variable [28]. We further compared those traits where the null hypothesis was rejected (i.e., the distribution was not-normal) using a nonparametric approach. 
For those cases, we applied the Kruskal-Wallis rank-sum test [29] with a posthoc multiple comparison test (R-pakage pgirmess).

\section{Results and Discussion}

\subsection{Fruiting Cuttings Allow Displaying the Variation for the Growing Conditions between 'Malbec' Clones}

We recorded the number of days from flowering to veraison and, at harvest, the cuttings were analyzed by recording cluster weight, berry number, berry weight, and degrees Brix (see below). Considering average values, we started the experiment with $49 \pm 6$ cuttings per clone (Table 1 ). From those, 59\% presented adequate roots, while $46 \%$ of the rotted cuttings reached the stage of fruit set. A large proportion ( $89 \%$ ) of the cuttings with a suitable fruit set were finally harvested (Table 1). These results evidenced the existence of natural variation for the analyzed development traits, particularly for rooting and fruit set. While the average values for these two traits were close to $50 \%$, extremes clones showed values from $27 \%$ to $80 \%$. The displayed inter-clonal variation was even higher than the observed for cultivars 'Gewurztraminer' and 'Pinot Noir' [21]. On the other hand, we observed a lower variation for the transition from fruit set to maturity (Table 1). Thus, fruit set seems to be a crucial step in establishing the fruiting cuttings, since most of the samples (89\%) reaching this stage were finally harvested (Table 1).

Table 1. Clone names, number of cuttings at the start, rotting, fruit-set, and harvest stages of the experiment.

\begin{tabular}{cccccccc}
\hline Clone & Start $(\boldsymbol{n})$ & Rooting $(\boldsymbol{n})$ & $\mathbf{( \% )}$ & Fruit Set $(\boldsymbol{n})$ & $\mathbf{( \% )}$ & Harvest $(\boldsymbol{n})$ & $\mathbf{( \% )}$ \\
\hline 501 & 47 & 32 & 68 & 25 & 78 & 22 & 88 \\
502 & 46 & 32 & 70 & 18 & 56 & 16 & 89 \\
503 & 43 & 26 & 60 & 15 & 58 & 11 & 73 \\
504 & 42 & 21 & 50 & 8 & 38 & 6 & 75 \\
505 & 46 & 25 & 54 & 8 & 32 & 5 & 63 \\
506 & 55 & 41 & 75 & 23 & 56 & 21 & 91 \\
507 & 55 & 43 & 78 & 15 & 35 & 12 & 80 \\
508 & 49 & 33 & 67 & 11 & 33 & 10 & 91 \\
510 & 54 & 32 & 59 & 17 & 53 & 16 & 94 \\
513 & 50 & 31 & 62 & 11 & 35 & 11 & 100 \\
514 & 50 & 14 & 28 & 7 & 50 & 6 & 86 \\
515 & 48 & 30 & 63 & 16 & 53 & 14 & 88 \\
$136 \_S$ & 42 & 22 & 52 & 12 & 55 & 10 & 83 \\
$136 \_N$ & 39 & 20 & 51 & 9 & 45 & 8 & 89 \\
711 & 52 & 20 & 38 & 9 & 45 & 9 & 100 \\
712 & 50 & 40 & 80 & 19 & 48 & 19 & 100 \\
713 & 53 & 25 & 47 & 16 & 64 & 15 & 94 \\
714 & 56 & 33 & 59 & 11 & 33 & 11 & 100 \\
42 & 41 & 20 & 49 & 8 & 40 & 8 & 100 \\
598 & 58 & 34 & 59 & 14 & 41 & 13 & 93 \\
595 & 56 & 41 & 73 & 11 & 27 & 11 & 100 \\
mean & 49 & 29 & 59 & 13 & 46 & 12 & 89 \\
sdt & 6 & 8 & 13 & 5 & 13 & 5 & 10 \\
max & 58 & 43 & 80 & 25 & 78 & 22 & 100 \\
min & 39 & 14 & 28 & 7 & 27 & 5 & 63 \\
\hline
\end{tabular}

\section{2. 'Malbec' Clones Show Significant Variation for Phenology and Berry Traits}

We found significant intra-varietal variation for three out of the five analyzed traits (i.e., cluster weight, berry number, and days from flowering to veraison; Table 2). Cluster weight (CW) showed significant differences between the different clones, (Table 2 and Figure 2a). This trait presented a mean of $21.3 \mathrm{~g}$ and a range between $11.1 \mathrm{~g}$ and $32.1 \mathrm{~g}$ (Table S1). 
Table 2. Kruskal-Wallis rank-sum $(H)$ test for phenology and berry traits. The $p$-value, $H$ statistic, and degrees of freedom ( $\mathrm{df}$ ) for the five analyzed characters are presented. DFV: days from flowering to veraison; CW: cluster weight; BN: berry number; BW: berry weight; Brix: degrees Brix. Significant $p$-values after the multiple comparison test are highlighted in bold.

\begin{tabular}{cccc}
\hline Trait & $\boldsymbol{p}$-Value & $\boldsymbol{H}$ & $\mathbf{d f}$ \\
\hline DFV & $<\mathbf{0 . 0 0 1}$ & 81 & 20 \\
CW & $<\mathbf{0 . 0 0 1}$ & 40 & 20 \\
BN & $<\mathbf{0 . 0 0 1}$ & 48 & 20 \\
BW & 0.03 & 33 & 20 \\
Brix & 0.01 & 37 & 20 \\
\hline
\end{tabular}
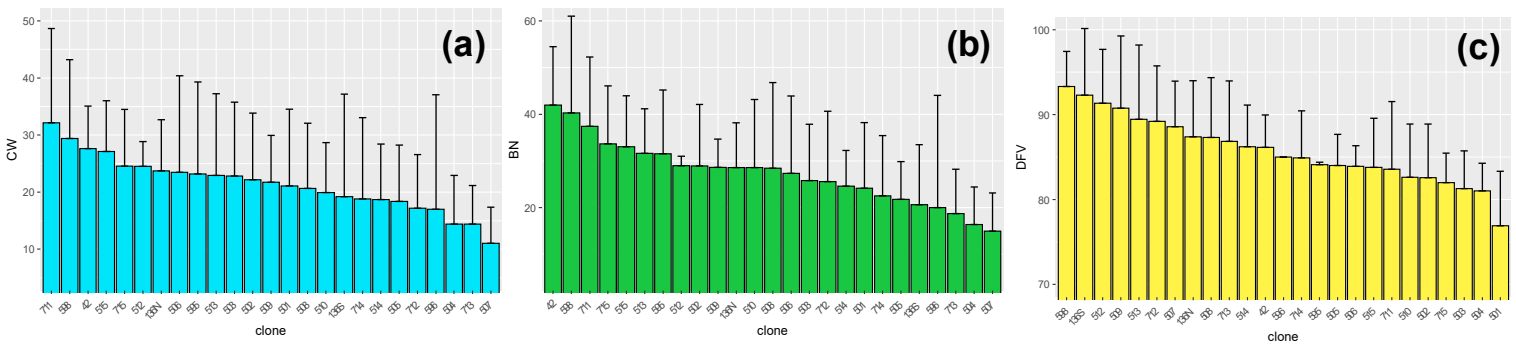

Figure 2. Mean values for phenology and agronomical traits between 21 'Malbec' clones. (a) Cluster weight; (b) Berry number; (c) Days from flowering to veraison. Error bars represent standard error of the calculated means.

Similarly, berry number (BN) also differed significantly within the evaluated clones (Table 2 and Figure 2b), with a mean of 27.0 berries/cluster and a ranging from 42 to 15 berries/cluster (Table S1). Considering the components of $\mathrm{CW}$ analyzed here (i.e., $\mathrm{BN}$ and $\mathrm{BW}$ ), $\mathrm{BN}$ emerged as the main determinant of $\mathrm{CW}$. While $\mathrm{CW}$ and $\mathrm{BN}$ were strongly correlated $(\mathrm{R}=0.81, p<0.001$; Figure $3 \mathrm{a})$, the correlation of CW and BW was clearly lower $(R=0.37, p<0.001$; Figure $3 b)$. The trait showing the more extreme differences between the clones was days from flowering to veraison (DFV). As described in Table 2, this trait presented an $H$ value of 87 for the Kruskal-Wallis rank-sum test with a $p$-value $<0.0001$. DFV showed a mean of 85.5 days with a range between 76.9 and 93.3 days. The higher differences were observed between clones 598 and 501, more than 16 days on average (Figure 2c; Table S1).

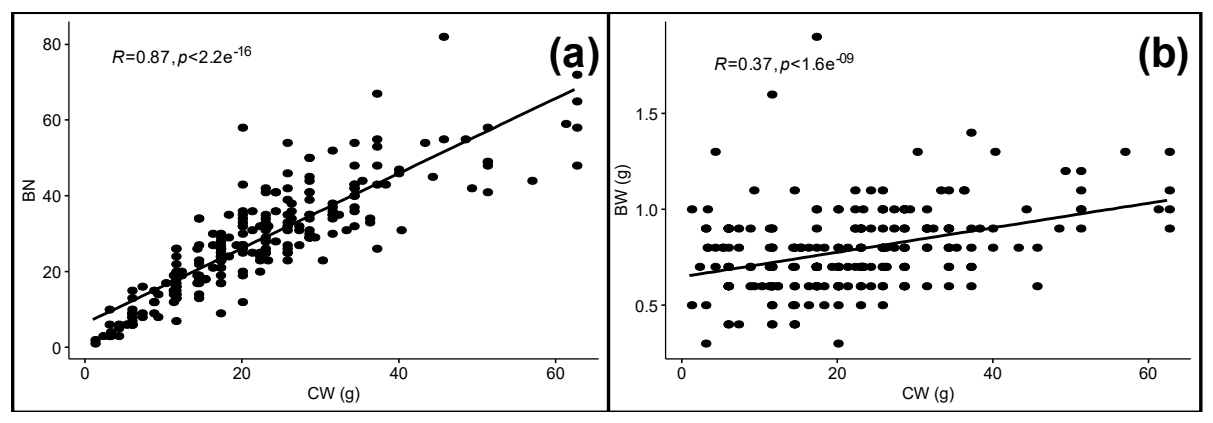

Figure 3. Pearson correlation of cluster weight (CW) and its determinants: (a) berry number (BN) and (b) berry weight (BW).

Intra-cultivar variation for agricultural and phenology traits was largely analyzed using field clones [30-34]. However, despite the proven usefulness of fruiting cuttings for study developmental and physiological traits $[2,4,15,19-24]$, just one work utilized this tool to compare clones of the same cultivar [15]. Particularly, significant differences for phenology traits were also observed in cultivar 'Tempranillo', where the authors analyzed cuttings from 13 clones, finding significant differences in 
the number of days that elapsed fruit set and mid-veraison [15]. The results of the present study and those reported in 'Tempranillo' [15] demonstrated the usefulness of grapevine fruit-bearing cuttings for comparing the phenological behavior of different clones from the same cultivar.

\section{Conclusions}

We presented here a detailed analysis of the intra-cultivar natural genetic variation for phenology and berry development traits within 21 'Malbec' accessions and we demonstrated that fruiting cuttings are a useful tool for the analysis of clonal diversity in the grapevine cultivar 'Malbec'. Berry traits allowed the differentiation between several clones, and particularly cluster weight displayed significant variations, explained mainly by the numbers of berries per cluster. Phenological diversity, evaluated by the phase between flowering and veraison, was the trait showing the most extreme differences within the clones, reaching more than 16 days between early and late clones. These results demonstrated the utility of exploring the grapevine intra-cultivar variation in searching for genotypes with delayed phenology with the help of fruiting cuttings. Those genotypes may probably present the potential to maintain some required characteristics under warm conditions and prospective adaptation to climate change.

Supplementary Materials: The following are available online at http://www.mdpi.com/2076-3417/10/16/5573/s1, Table S1: Summary values (mean, standard error and $\mathrm{n}$ ) for traits showing significant differences between the 21 'Malbec' clones: days from flowering to veraison (DFV), cluster weight (CW) and berry number (BN), Figure S1: Phenological events recorded during the growing season. Temperature conditions during the 2018-2019 season (orange line) and historic (last 17 years, blue line).

Author Contributions: Conceptualization, D.L. and C.M.; methodology, C.M., S.v.H., D.B., C.S. and D.L.; software, S.v.H. and D.L.; formal analysis, S.v.H. and D.L.; investigation, S.v.H. and C.M.; resources, L.B., D.B., C.S.; data curation, S.v.H.; writing—original draft preparation, S.v.H.; writing-review and editing, D.L.; project administration, L.B.; funding acquisition, C.S. and D.L. All authors have read and agreed to the published version of the manuscript.

Funding: This work was funded by Agencia Nacional de Promoción de la Investigación, el Desarrollo Tecnológico y la Innovación, grant numbers: ANR INT 3500-0005 and PICT2015-0822. Silvina van Houten acknowledges the National University of Cuyo (SIIP-UNCUYO) for her postgraduate fellowship.

Conflicts of Interest: The authors declare no conflict of interest.

\section{References}

1. Voosen, P. New climate models predict a warming surge. Science (80-. ) 2019. [CrossRef]

2. Carbonell-Bejerano, P.; Santa María, E.; Torres-Pérez, R.; Royo, C.; Lijavetzky, D.; Bravo, G.; Aguirreolea, J.; Sánchez-Díaz, M.; Antolín, M.C.C.; Martínez-Zapater, J.M.J.M. Thermotolerance Responses in Ripening Berries of Vitis vinifera L. cv Muscat Hamburg. Plant Cell Physiol. 2013, 54, 1200-1216. [CrossRef]

3. Pastore, C.; Dal Santo, S.; Zenoni, S.; Movahed, N.; Allegro, G.; Valentini, G.; Filippetti, I.; Tornielli, G.B. Whole Plant Temperature Manipulation Affects Flavonoid Metabolism and the Transcriptome of Grapevine Berries. Front. Plant Sci. 2017, 8, 929. [CrossRef]

4. Lecourieux, F.; Kappel, C.; Pieri, P.; Charon, J.; Pillet, J.; Hilbert, G.; Renaud, C.; Gomès, E.; Delrot, S.; Lecourieux, D. Dissecting the Biochemical and Transcriptomic Effects of a Locally Applied Heat Treatment on Developing Cabernet Sauvignon Grape Berries. Front. Plant Sci. 2017, 8, 53. [CrossRef] [PubMed]

5. Movahed, N.; Pastore, C.; Cellini, A.; Allegro, G.; Valentini, G.; Zenoni, S.; Cavallini, E.; D’Incà, E.; Tornielli, G.B.; Filippetti, I. The grapevine VviPrx31 peroxidase as a candidate gene involved in anthocyanin degradation in ripening berries under high temperature. J. Plant Res. 2016, 129, 513-526. [CrossRef] [PubMed]

6. Sadras, V.O.; Moran, M.A. Nonlinear effects of elevated temperature on grapevine phenology. Agric. For. Meteorol. 2013, 173, 107-115. [CrossRef]

7. Sadras, V.O.; Petrie, P.R. Climate shifts in south-eastern Australia: Early maturity of Chardonnay, Shiraz and Cabernet Sauvignon is associated with early onset rather than faster ripening. Aust. J. Grape Wine Res. 2011, 17, 199-205. [CrossRef] 
8. Martínez-Lüscher, J.; Kizildeniz, T.; Vučetić, V.; Dai, Z.; Luedeling, E.; van Leeuwen, C.; Gomès, E.; Pascual, I.; Irigoyen, J.J.; Morales, F.; et al. Sensitivity of Grapevine Phenology to Water Availability, Temperature and $\mathrm{CO}_{2}$ Concentration. Front. Environ. Sci. 2016, 4, 48. [CrossRef]

9. Duchêne, E.; Huard, F.; Dumas, V.; Schneider, C.; Merdinoglu, D. The challenge of adapting grapevine varieties to climate change. Clim. Res. 2010, 41, 193-204. [CrossRef]

10. Torregrosa, L.; Bigard, A.; Doligez, A.; Lecourieux, D.; Rienth, M.; Luchaire, N.; Pieri, P.; Chatbanyong, R.; Shahood, R.; Farnos, M.; et al. Developmental, molecular and genetic studies on grapevine response to temperature open breeding strategies for adaptation to warming. J. Int. Sci. Vigne Vin 2017, 51, 155-165. [CrossRef]

11. Conde, C.; Silva, P.; Fontes, N.; Dias, A.C.P.; Tavares, R.M.; Sousa, M.J.; Agasse, A.; Delrot, S.; Geros, H. Biochemical changes throughout grape berry development and fruit and wine quality. Food 2007, 1, 1-22.

12. Caballero, A.; Segura, A. The quest for lower alcoholic wines. Microb. Biotechnol. 2017, 10, 238-241. [CrossRef] [PubMed]

13. Duchêne, E. How can grapevine genetics contribute to the adaptation to climate change? OENO One 2016, 50. [CrossRef]

14. Van Leeuwen, C.; Darriet, P. The Impact of Climate Change on Viticulture and Wine Quality. J. Wine Econ. 2016, 11, 150-167. [CrossRef]

15. Arrizabalaga, M.; Morales, F.; Oyarzun, M.; Delrot, S.; Gomès, E.; Irigoyen, J.J.; Hilbert, G.; Pascual, I. Tempranillo clones differ in the response of berry sugar and anthocyanin accumulation to elevated temperature. Plant Sci. 2018, 267, 74-83. [CrossRef] [PubMed]

16. This, P.; Lacombe, T.; Thomas, M.R. Historical origins and genetic diversity of wine grapes. Trends Genet 2006, 22, 511-519. [CrossRef]

17. Carbonell-Bejerano, P.; Royo, C.; Torres-Pérez, R.; Grimplet, J.; Fernandez, L.; Franco-Zorrilla, J.M.J.M.; Lijavetzky, D.; Baroja, E.; Martínez, J.; García-Escudero, E.; et al. Catastrophic unbalanced genome rearrangements cause somatic loss of berry color in grapevine. Plant Physiol. 2017, 175, 786-801. [CrossRef]

18. Martínez-Zapater, J.M.M.; Carmona, M.J.J.; Díaz-Riquelme, J.; Fernández, L.; Lijavetzky, D. Grapevine genetics after the genome sequence: Challenges and limitations. Aust. J. Grape Wine Res. 2010, 16, $33-46$. [CrossRef]

19. Mullins, M.G.; Rajasekaran, K. Fruiting Cuttings - Revised Method for Producing Test Plants of Grapevine Cultivars. Am. J. Enol. Vitic. 1981, 32, 35-40.

20. Ollat, N.; Geny, L.; Soyer, J.-P. Grapevine fruiting cuttings: Validation of an experimental system to study grapevine physiology. I. Main vegetative characteristics. OENO One 1998, 32, 1. [CrossRef]

21. Lebon, G.; Duchene, E.; Brun, O.; Clement, C. Phenology of Flowering and Starch Accumulation in Grape (Vitis vinifera L.) Cuttings and Vines. Ann Bot 2005, 95, 943-948. [CrossRef] [PubMed]

22. Vaillant-Gaveau, N.; Maillard, P.; Wojnarowiez, G.; Gross, P.; Clément, C.; Fontaine, F. Inflorescence of grapevine (Vitis vinifera L.): A high ability to distribute its own assimilates. J. Exp. Bot. 2011. [CrossRef] [PubMed]

23. Dai, Z.W.; Léon, C.; Feil, R.; Lunn, J.E.; Delrot, S.; Gomès, E. Metabolic profiling reveals coordinated switches in primary carbohydrate metabolism in grape berry (Vitis vinifera L.), a non-climacteric fleshy fruit. J. Exp. Bot. 2013, 64, 1345-1355. [CrossRef] [PubMed]

24. Kizildeniz, T.; Pascual, I.; Irigoyen, J.J.; Morales, F. Using fruit-bearing cuttings of grapevine and temperature gradient greenhouses to evaluate effects of climate change (elevated $\mathrm{CO}_{2}$ and temperature, and water deficit) on the cv. red and white Tempranillo. Yield and must quality in three consecutive growin. Agric. Water Manag. 2018, 202, 299-310. [CrossRef]

25. Ollat, N.; Gaudillere, J.P. The Effect of Limiting Leaf Area During Stage I of Berry Growth on Development and Composition of Berries of Vitis vinifera L. cv. Cabernet Sauvignon. Am. J. Enol. Vitic. 1998, 49, 251-258.

26. R Core Team. R: A Language and Environment for Statistical Computing. R Found. Stat. Comput. 2019. Available online: http://finzi.psych.upenn.edu/R/library/dplR/doc/intro-dplR.pdf (accessed on 26 July 2020).

27. Rstudio Team. RStudio: Integrated development for, R. RStudio, Inc., Boston MA. RStudio 2016, 42, 14.

28. Royston, P. Remark AS R94: A Remark on Algorithm AS 181: The W-test for Normality. J. R. Stat. Soc. Ser. C (Appl. Stat.) 1995, 44, 547-551. [CrossRef]

29. Hollander, M.; Wolfe, D.A.; Chicken, E. Nonparametric Statistical Methods, 3rd ed.; Hollander, M., Wolfe, D.A., Chicken, E., Eds.; John Wiley \& Sons: New York, NY, USA, 2003; ISBN 9780470387375. 
30. Muñoz, C.J.; Gomez-Talquenca, S.; Chialva, C.; Ibáñez, J.; Martinez-Zapater, J.M.J.M.; Peña-Neira, A.; Lijavetzky, D.; Pena-Neira, A.; Lijavetzky, D. Relationships among gene expression and anthocyanin composition of Malbec grapevine clones. J. Agric. Food Chem. 2014, 62, 6716-6725. [CrossRef]

31. Tortosa, I.; Escalona, J.M.; Douthe, C.; Pou, A.; Garcia-Escudero, E.; Toro, G.; Medrano, H. The intra-cultivar variability on water use efficiency at different water status as a target selection in grapevine: Influence of ambient and genotype. Agric. Water Manag. 2019, 223, 105648. [CrossRef]

32. Grimplet, J.; Tello, J.; Laguna, N.; Ibáñez, J. Differences in Flower Transcriptome between Grapevine Clones Are Related to Their Cluster Compactness, Fruitfulness, and Berry Size. Front. Plant Sci. 2017, 8, 632. [CrossRef] [PubMed]

33. Pelsy, F.; Hocquigny, S.; Moncada, X.; Barbeau, G.; Forget, D.; Hinrichsen, P.; Merdinoglu, D. An extensive study of the genetic diversity within seven French wine grape variety collections. Theor. Appl. Genet. 2010, 120, 1219-1231. [CrossRef] [PubMed]

34. Lorenzo, M.R.; Sabalza, F.C.; Sarasa, A.S.; Abad, F.J.; Zapater, J.M.M.; Marcos, J.I. Intra-varietal diversity for agronomic traits in'Garnacha Blanca'. Vitis J. Grapevine Res. 2019, 58, 33-35.

(C) 2020 by the authors. Licensee MDPI, Basel, Switzerland. This article is an open access article distributed under the terms and conditions of the Creative Commons Attribution (CC BY) license (http://creativecommons.org/licenses/by/4.0/). 